\title{
TURNING SOCIAL MEDIA USERS INTO BRAND FOLLOWERS: WHAT WORKS?
}

\author{
Kahni Kashiparekh ${ }^{1}$ \\ ${ }^{1}$ Symbiosis Institute of Business Management, Bengaluru
}

\begin{abstract}
With the rise of new age media, social media marketing has become one of the most powerful tools in all marketers' arsenal, and brands' social media pages have become a way for companies to expand their awareness and customer base. In this paper, factors that attract a social media user to "follow" and engage with brands have been studied, namely, the content and tone used by brands on their social media, online brand communities for the brand, and the brand's online activism have been identified as some of the important factors. For determination of results, factor analysis through principle axis factoring and varimax rotation has been done on SPSS v23.0. The results indicate that users care about whether brands take a stand on social, economic and political causes, and brand activism is therefore the most important factors for Gen-Z and Millennials in their decision to turn into brand followers. At the same time, users also want to feel like they belong to the brand's ecosystem and that the brands look at them as important stakeholders, which is achieved through brand communities.

This study will help marketers plan their social media marketing activities more effectively so as to give users what they want, and in turn increase their online reach.
\end{abstract}

Keyword: Social Media Marketing, Brand Followers, Content Type, Online Brand Activism, Online Brand Communities

\section{Introduction}

Over the past decade, one particular area of communication has gained prominence, and given the incredible amount of importance it receives in marketing strategies now, it seems that managers have found an extremely effective medium for brand communication and engagement with consumers. We are talking about Social Media, of course.

Social media are forms of communication tools having Web 2.0 attributes, i.e., being participatory, collaborative, and having and user-empowering and knowledge sharing tools available on the web. (Robinson, 2007)

The Social Media space is not narrow or unidimensional, rather, it is divided into three different categories, i.e., mobile social media, social media networking sites, and blogs. (IAB 2009). However, existing research suggests that despite the social media usage varying based on the users' personality \& their comfortableness with the online mechanisms, no personality variables are connected with the intention to use social media (Ross, et al., 2009).

Rather, consumers use social media platforms to follow a brand's promotional campaigns and its products. (Leggat, 2010; Mangold and Foulds, 2009)

A joint report from Hootsuite \& We Are Social - the Digital 2020 July Global Statshot report found that for the first time, over half of the global population is now using social media. When we talk about the implication of this number for the area of marketing, $27 \%$ of internet users have said that they find new brands and products through paid social media ads. However, despite the continued popularity and usage of social media by both marketers and consumers, empirical research studying the factors that affect a consumer's decision to "follow" a brand on social media is relatively understudied.

To this extent, this study tries to investigate why consumers "follow" brands on social media networks, and provides insights about the factors that are of the highest importance to young Indian adults, i.e., those under the age group of 18-30 years, when they are forming the intention to hit the "follow" button.

The focus group has been selected after a careful review of the statistics and information regarding the internet penetration and usage of social media in the country: As of 3rd quarter, $2017,41 \%$ of the worldwide population of internet users who follow brands or share a brands' posts on social media each month were from the Asia-Pacific region. This number is likely to have increased. As of December 2019, India ranked 2 nd in terms of internet users, with $560 \mathrm{mn}$ users. In terms of social media penetration, the top social platforms are Youtube (82\%), Facebook (76\%), Whatsapp (70\%) and Instagram (64\%) respectively. (Statista 3rd Quarter 2019) "Millennials" and "GenZ" are the two main contributors of the usage of social media in India - As of 2019, $52.3 \%$ of SM searches came through millennials, and $28.4 \%$ of SM conversations came through Gen Z. (Statista, 2019)

Given these figures, the Indian Millennial and Gen $\mathrm{Z}$ population provides a valid dataset to study the various factors of a brand's social media presence that affect a user's decision to engage socially, and arrive at results that can be generalized.

Review of Literature (reformat lit review and check references)

The research of Sands, Harper, \& Ferraro, 2011 and Corstjens 
and

Umblijs, 2012 had suggested that social media was becoming a game-changer and would have a major effect on business, and would transform consumer behaviour, consumer-brand relationships, and conventional brand practices. (Kaplan \& Haenlein, 2010; Thurau, et al., 2010)

That is indicated in the particular piece of knowledge that consumers now have near-boundless chances to engage with brands (Helm and Jones, 2010; Christodoulides, G., Jevons, C., \& Bonhomme, J., 2012). This increased brand access demands that branding and marketing strategies change towards engagement platforms. (Doorn, et al., 2010; Naylor, Lamberton, \& West, 2012)

There are various antecedents that affect a consumer's perception of brands and their decision to engage with them online.

In the customers' eyes, social media sites are service channels where they can be involved with businesses on a real-time basis (Leggat, 2010). Social media is a platform wherein users can express themselves candidly, and keep themselves updated about what people or/and brands they are interested in are doing, and escape their routine (Dong-Hun, L. (2010)).

This provides brands with an enormous opportunity - through social media, now companies have the means to converse with tens of thousands of customers at the same time. (Kalwani, M., \& Narayandas, N. (2011))

Social Media is used by social media marketers to get their brands involved in the consumers' personal social networks. As a main differentiator with regards to any other form of media, on social media, marketers produce brand-centric content that inspires instant interaction of the consumer with the marketer.

The ability to communicate with such a wide audience simultaneously means that information can be delivered in a quick manner - through feedback, and has an important and enduring impact by creating long-lasting relationships with customers. The establishment and maintenance of these relationships calls for them to be human as well as customized. Thus, in the virtual world, continuous conversation is required for the establishment of these relationships.

According to Muntinga, Moorman, \& Smit, 2011, "brand followers" are inspired people who willingly receive branded content when they 'follow' particular brands on Twitter. They aim to 'consume' brand-centric content and engage in E-Word of Mouth by showcasing brand information posted on their 'tweetdecks'. Thus, brand followers take part in user-to-user as well as user-to-content interaction (Shao, 2009), or make their own

contribution to content associated with the brand. While these definitions were limited to their study of the social network Twitter, they can be extended to fit to other social media networks as well.

However, customers prefer the social media content to be updated and popular. Erdoğmuş \& Cicek (2012) found that the content relevancy, and the its popularity among friends and peers positively affect a customer's brand loyalty on social media. They suggested that companies must keep themselves updated about where the customers' interests lie, their activities, and their pre-existing perspectives in life; and that brands and their campaigns should be fun, pleasing, and unique when they try to engage with customers on social media.

A number of brands have utilised entertaining content on social media to boost consumer engagement recently. Making use of creative content allows brands to create a "buzz" on social media. Different kinds of online marketing campaigns and inventive events that brands frequently carry out on social media (Miller and Lammas, 2010), draw in a number of people looking for entertainment.

Kwon, Kim, Sung, \& Yoo (2014) suggest that the fundamental cue to social media marketing success is providing content that is both compelling and informative, with inherent societal value to stimulate electronic word of mouth.

It is thus still unclear in the existing literature, as to what the marketing effectiveness of Marketer Generated Content, which tends to be overly positive, is on the user's decision to follow the brand on social media.

\section{H1: The content and tone posted on social media brand pages affects user intent to "follow" the brand.}

On social media networks, customers can aid in building brands; share information; have conversations and trade opinions among fellow customers; and also talk to the brand itself, through questions, complaints, or compliments. (Patterson, A. (2012))

In recent times, more consumers are involving themselves on social sites to converse with other customers and with brands (Kelley \& Alden, 2016). Marketers are trying to understand how to establish and sustain communities so as to increase the value their customers derive (Martínez-López et al., 2016). By making use of, and by marketing brand communities, Online Brand Communities (OBC) specifically, brands successfully steer clear of existing consumer aversion to conventional marketing initiatives centred on traditional media. 
Laroc

he, Habibi, Richard, \& Sankaranarayanan (2012) opined that brand communities on social media have a beneficial result for brands, the processes of value creation $\&$ on the quality of service (Ellahi and Bokhari, 2013).

An OBC is considered as a means of information search, forming social relations and of creating a distinct identity that is aligned with the brand. The ease with which users can participate in social communities online, eliminates the physical as well as the temporal barriers, thereby boosting the chances of involvement of consumers who may not have been capable of, or willing to do so earlier.

The need or desire for information is a motivator for people to consume content that is related to the brands.

According to Thurau \& Walsh, 2003, checking reviews by other customers is driven partially by an information need, and Hsu and Liao (2007) suggested that feelings of community inspire involvement in them.

Users also look at brands and their content in social media communities as a means to entertain themselves, rather than solely for knowledge-search motivations.

According to Martínez-López, et al., engagement with consumers is important in describing a member's community involvement, and they suggest that $\mathrm{OBC}$ experience and trust, are important antecedents, both directly as well as indirectly, via recognition of the community.

Consumers pay attention to the content quality, the brands' responsiveness and the regularity with which they post updates - but that's not all, they also look at the number of people following the brand, and the magnitude of their communications with it. These findings contradict the popularly accepted notion that consumers are more interested in the content that brands share on their social media than the number of followers and "likes". Certainly, in the social media space, these figures are viewed as determinants of the credibility of the brand (Pentina, Gammoh, Zhang, \& Mallin, 2013).

However, the existing literature has not yet studied what aspects of OBC's affect a person's decision to "follow" and further engage with brands on social platforms, thus,

\section{H2: The presence of reliable OBCs affects a person's social media interactions with that brand.}

Social consumers now expect brands to be more socially conscious $-70 \%$ of the people surveyed for the Digital 2020 July Global Statshot report, said that they feel it is crucial for brands to be vocal and take a public stand on political and social issues; while $47 \%$ expected brands to speak up about such issues on

social media, and $53 \%$ of consumers expect brands to be transparent about their company's values on social media.

Consumers are no longer quiet individuals, they have transformed into a loud and collective - wanting to bring worldwide 'change' (Libai, et al., 2010; Patterson, 2012).

For them, social media is a means to make their point heard and consequently, having a positive effect on the humanitarian movements, political arguments, or environmental and economic issues (Beirut, 2009).

The Marketing Science Institute, in 2016, pointed out that the matter of whether brands should in fact take such stands, as one of the important issues surfacing in the near future of marketing, and it emphasized on the fact that it would become pertinent for managers to understand if chasing controversy is really going to benefit their brand or harm it.

Brand activism can thus be described as brands taking public stands on divisive issues. (Kotler \& Sarkar, 2017)

Consumers often juxtapose their persona with the persona and symbolism that is linked with a specific brand. Particularly, a higher self-brand similarity can make the consumer humanise or in some way personify the brand (Fournier, S.,1998), and thus, hold decidedly positive attitudes towards that brand (Escalas \& Bettman, 2005).

Brand activism therefore gives consumers a chance to evaluate the extent of similarity between the self and the brand when we talk of moral judgments, meaning, it lets consumers decide if a brand's moral standing aligns with their personal morals or not.

Consumer brand identification theory (e.g., Sauer, Ratneshwar, \& Sen, 2012) suggests a high similarity between the self and the brand, must ideally result in a stronger identification of the self-brand and, therefore, to greater favourable brand attitudes.

Authenticity is important to consumers now - they are inclined to engage with brands if their symbolic meanings correspondent with the way they perceive themselves (Schouten, J.W. 1991). If consumers see a brand's symbolic meanings, as depicted in their online community on social media, to be aligned with their personal values and credence they will be more inclined to consume brand's social content.

Organizations that realize when to participate in - and, when to avoid divisive conversations - let people know that they care, and are generally viewed as a good point to include in the conversation; as against brands which barge into conversations that were not 
s' to begin with.

The subject of brand activism and its effect on consumer attitudes, and their intention to follow a brand on social media have so far been understudied, and thus we come to our final hypothesis;

H3: A brand's online brand activism positively affects consumer attitudes towards following a brand on social media

\section{Data and Methodology}

A random sampling method was adopted to gather primary data, for which an online structured questionnaire was used with 271 existing social media users responding; from this, a sample of 212 qualified for the study.

In the questionnaire, one filter question was employed to filter out the respondents to derive the sample that was eligible for the study. The filter question asked the respondents if they followed any brands on any social media platforms. If the answer was positive, then they were administered the next set of questions.

The questionnaire was developed to measure the factors that affected young social media users based on which they decided to "follow" the brand on any social networking platforms, and a five-point Likert scale, covering points from 1 to 5 , where a 1 meant "Strongly Disagree", to a 5 which meant "Strongly Agree". This scale was used in terms of importance of the attributes in social media. The responses were noted using 15 statements measured on the importance scale. The data received from respondents was put through Factor Analysis through dimension reduction, with principle axis factoring and varimax rotation, and eigen values were used to derive the number of factors. The factor analysis was done on the SPSS 23.0 software.

Since, the interest was in the participants' intent to become brand followers, it was considered fair to collect data from people who already do follow one or more brands on social media. The key informant method was used and the responses of only those customers was tested who are already brand followers.

The questions for measuring consumers' reasons to "follow" brands on social media were arrived at after careful consideration of the existing literature. The items were constructed on the following factors: the existence of online brand communities, online reputation management by the brand, the content type posted, and brand activism on social media.

\section{Results and Discussion}

5.1 Analysis of Data

The data collected for the study revealed that about $61.79 \%$ respondents were male, the rest $37.73 \%$ being female respondents (Table 1$)$. A majority $(56.13 \%)$ of the respondents were between $18-23$ years old, $42.92 \%$ were between 24 to 29 years old, and only $0.95 \%$ were between $30-35$ years old (Table 1). Hence, a large chunk of the respondents belonged to the younger generation, where the internet penetration and adoption of social media is advanced, as evidenced by the stats

\begin{tabular}{|c|c|c|c|c|}
\hline \multicolumn{5}{|c|}{ Respondent Profile } \\
\hline Sr. & \multicolumn{2}{|c|}{ Description } & No. of & Percentage \\
\hline \multirow[t]{3}{*}{1.} & \multirow[t]{3}{*}{ Gender } & Male & 131 & 61.79 \\
\hline & & Female & 80 & 37.74 \\
\hline & & $\begin{array}{l}\text { Prefer not } \\
\text { to say }\end{array}$ & 1 & 0.47 \\
\hline \multirow[t]{3}{*}{2.} & \multirow[t]{3}{*}{ Age } & $18-23$ & 119 & 56.13 \\
\hline & & $24-29$ & 91 & 42.92 \\
\hline & & $30-35$ & 2 & 0.95 \\
\hline \multirow[t]{4}{*}{3.} & \multirow{4}{*}{$\begin{array}{l}\text { Daily } \\
\text { Social } \\
\text { Media } \\
\text { Usage } \\
\text { (avg.) }\end{array}$} & $<1$ Hour & 23 & 10.85 \\
\hline & & $\begin{array}{l}1 \text { to } 3 \\
\text { Hours }\end{array}$ & 118 & 55.66 \\
\hline & & 3-5 Hours & 54 & 25.47 \\
\hline & & $>5$ Hours & 17 & 8.02 \\
\hline
\end{tabular}

mentioned earlier.

Table 1: Respondent Profile \& Social Media Usage

\subsection{Influence of Factors on the Choice to Become Brands Followers on Social Media}

To generate factors that have been considered meaningful by the respondents for following brands on social media, factor analysis was applied. For the factor analysis, 15 items were considered for checking reliability. Kaiser-Meyer-Olkin value $(0.735)$ indicates the reliability of the factor analysis. To check whether correlations exist between the variables, Bartlett's test of sphericity was applied. A smaller value $(0.000<0.05)$ indicated that the variables are not correlated and hence the data collected is feasible for a reduction technique. Further, a reliability analysis was undertaken, and the Cronbach's Alpha was found to be 0.785 , greater than the acceptable limit of 0.7 . 
The

data collected was used in the principal component analysis method utilizing varimax rotation. Factor loadings greater than 0.5 were considered for the variables. The output matrix (Table 2) depicts the factor loadings and factors extracted along with items. This four-factor model is also supported by the scree test (Figure 1). In the analysis, the Eigen values started to level off after the fourth factor. The results generated four components, accounting for $54.839 \%$ of the total variance. These components each accounted for $24.498 \%$, $11.923 \%, 9.741 \%$ and $8.667 \%$ of the overall variance, suggesting appropriateness of the factor analysis to be responsible for identifying underlying constructs.

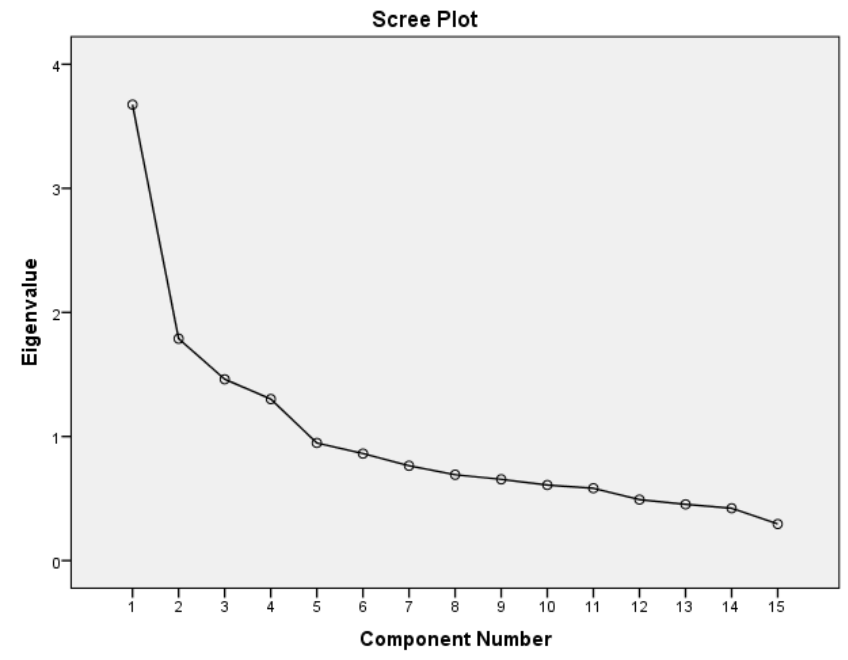

Figure 1. Scree Plot

The fifteen scale items utilised in the factor analysis yielded four extractions that explained $54 \%$ of the total variance. The table given below (Table 2) groups together the various attributes under the factors based on their factor loadings.

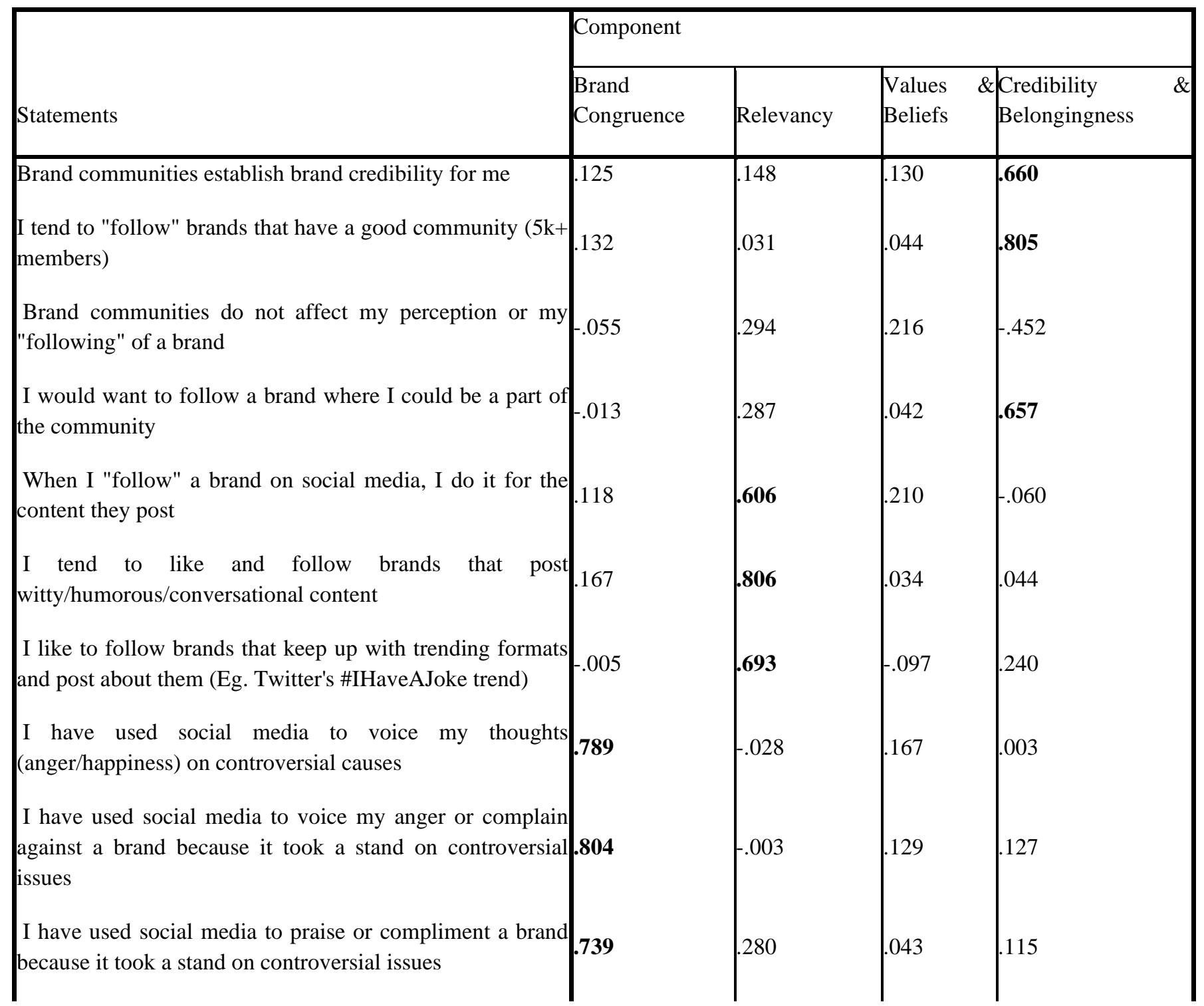


$\begin{aligned} & \text { I like to "follow" such brands that take a definitive stand } \\ & \text { on divisive issues } \\ & \text { I follow some brands purely for their societal ads } \\ & \text { It matters to me if a brand I like or feel loyal towards, } \\ & \text { takes a different stand from my beliefs on any cause or } \\ & \text { issue } \\ & \text { I will not engage (follow/purchase from) with brands that } \\ & \text { go against my values } \\ & \text { I would stop using a product I like if I find out that the } \\ & \text { brand has negative views about a cause or an issue }\end{aligned} \mid .168$

Table 2: Output Matrix

\subsection{Discussion}

\subsubsection{Factor 1: Brand Congruence}

This factor was based on scale items from the variable under consideration, "Online Brand Activism" and dealt with how comfortable a consumer was to voice their own opinions about6. any brand and its dealings and opinions. It had an eigen value of 3.675 and explained $24.498 \%$ of the variance. This factor has the most bearing on the decision of the consumer to follow a brand on social media, and hence, brands must take steps to ensure an online environment where the consumers can voice their happiness or dissatisfaction with a brand and feel heard, while at the same time, they should put an emphasis on showing their societal side online.

\subsubsection{Factor 2: Relevancy}

This factor was based on scale items from the variable "Content Type" and one scale item from the variable "Online7. Brand Activism". It has an eigen value of 1.788 and explains $11.923 \%$ of the total variance. This factor comes out as the second most critical factor for turning a consumer into a brand follower on social media. This suggests that the social media manager for the brand's social pages should ensure topical content that is trending, as and when a trend takes over the internet.

\subsubsection{Factor 3: Values and Beliefs}

This factor was based on the remaining scale items under the variable "Online Brand Activism" - it has an eigen value of 1.461 and explains $9.741 \%$ of the total variance. It groups attributes like 'brand values' and 'loyalty'.

\subsubsection{Factor 4: Credibility \& Belongingness}

This factor was based on the scale items under the variable "Online Brand Communities" and groups attributes such as 'perception', ‘community strength' and 'belongingness'. This

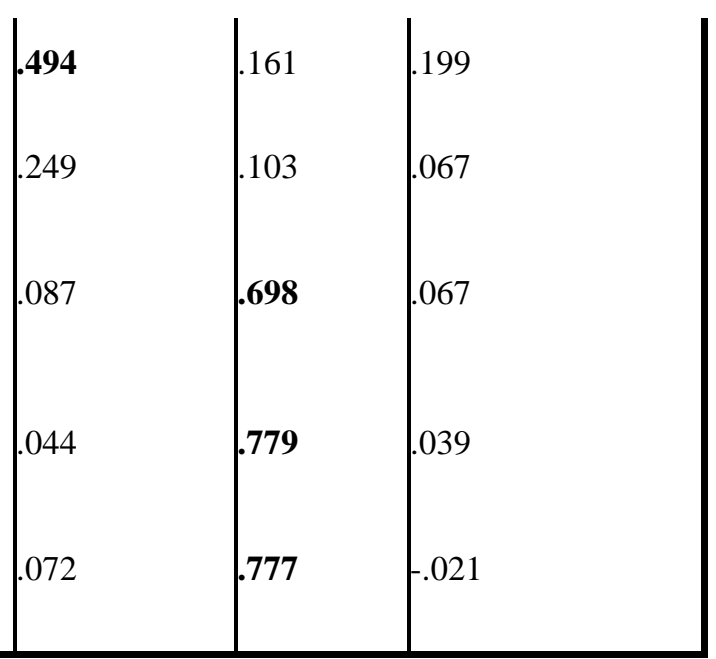

factor has an eigen value of 1.302 and explains $8.677 \%$ of the total variance.

This factor suggests that brands should put in efforts to create such an image that they inspire a strong feeling of attachment to it or its products and thus form the basis of an online community.

\section{Implications of the Study}

The study sheds light on new factors that affect a social media users' decision to become brand followers. In particular, online brand activism is seen as an important factor, and brands can no longer stay quiet in the current age where social media users voice their opinions about every issue - the onus now falls on the marketers and brands to craft their content in a way that does not make them seem neutral on issues of importance. Marketers also need to make sure that their brands' social media followers find a sense of belongingness, and find the social media content relatable yet humorous.

\section{Scope of Future Study}

Social Media is a dynamic space, and new platforms are regularly introduced to the market and gain importance in the blink of an eye - different social media platforms cater to different segments and thus users have different codes of behavior on different platforms. For example, LinkedIn as a social media platform is a professional network, and thus, the results of this study cannot be generalized to fit all kinds of social media platforms. Future studies can be focused towards user behaviors across different social platforms, and how they affect user engagement, also, another area of study that is as yet underexplored is how user engagement on social media is converted into a revenue stream.

\section{Conclusion}

Social Media is a booming space, and works quite differently from traditional marketing channels, what works for a brand in traditional marketing messages does not necessarily work in the online space of social media, which by its own right is becoming the "place to be" for brands. Users of social media 
tend to be impulsive when it comes to their own profiles, but that is clearly not the case when they have to engage with a brand in the social networking space - brands have to work to earn that one more follower, they have to prove to the social media users that they have something worth their time. The review of literature gave insights into a few choice factors that seemed to be critical to this process, and the findings of the study clearly suggest that Online Brand Activism and Content Type are two of the most important factors when we talk about the factors that turn a social media user into a brand follower. This means that brands should take extra steps to stay updated and post content and take stands on issues in real time - as and when the situation arises. At the same time, consumers also care about the existence of communities and would like to be a part of the same, if they perceived them to lend credibility to the brand or if being a part of the community made them feel a sense of belongingness. This concludes the fact that consumers follow brands on social media if they feel that the brand actively puts their thoughts out, and stays relevant with their content in the ever-dynamic social media space.

\section{References}

[1]. Beirut. (2009). Why do people really tweet? The psychology behind tweeting! http://blog.thoughtpick.com/2009/08/why-dopeoplereally-tweet-the-psychology-behindtweeting.html

[2]. Christodoulides, G., Jevons, C., \& Bonhomme, J. (2012). Memo to marketers: Quantitative evidence for change: How user-generated content really affects brands. Journal of advertising research, 52(1), 53-64.

[3]. Corstjens, M., \& Umblijs, A. (2012). The power of evil: The damage of negative social media strongly outweigh positive contributions. Journal of advertising research, 52(4), 433-449.

[4]. Dong-Hun, L. (2010). Korean consumer \& society: growing popularity of social media and business strategy. Seri Quarterly, 3(4), 112.

[5]. Ellahi, A., \& Bokhari, R. H. (2013). Key quality factors affecting users' perception of social networking websites. Journal of Retailing and Consumer Services, 20(1), 120-129.

[6]. Erdoğmuş, İ. E., \& Cicek, M. (2012). The impact of social media marketing on brand loyalty. ProcediaSocial and Behavioral Sciences, 58, 1353-1360.

[7]. Escalas, J. E., \& Bettman, J. R. (2005). Self-construal, reference groups, and brand meaning. Journal of consumer research, 32(3), 378-389.

[8]. Fournier, S. (1998). Consumers and their brands: Developing relationship theory in consumer resear

ch. Journal of consumer research, 24(4), 343-373.

[9]. Helm, C., \& Jones, R. (2010). Extending the value chain-A conceptual framework for managing the governance of co-created brand equity. Journal of Brand Management, 17(8), 579-589.

[10]. Hennig-Thurau, T., Malthouse, E. C., Friege, C., Gensler, S., Lobschat, L., Rangaswamy, A., \& Skiera, B. (2010). The impact of new media on customer relationships. Journal of service research, 13(3), 311330.

[11]. Hennig-Thurau, T., Walsh, G., \& Walsh, G. (2003). Electronic word-of-mouth: Motives for and consequences of reading customer articulations on the Internet. International journal of electronic commerce, 8(2), 51-74.

[12]. Kaplan, A. M., \& Haenlein, M. (2010). Users of the world, unite! The challenges and opportunities of Social Media. Business horizons, 53(1), 59-68.

[13]. Kelley, J. B., \& Alden, D. L. (2016). Online brand community: through the eyes of self-determination theory. Internet Research.

[14]. Kotler, P., \& Sarkar, C. (2017). Finally, brand activism. The Marketing Journal, 9, 2017.

[15].

[16]. Laroche, M., Habibi, M. R., Richard, M. O., \& Sankaranarayanan, R. (2012). The effects of social media based brand communities on brand community markers, value creation practices, brand trust and brand loyalty. Computers in Human Behavior, 28(5), 1755-1767.

[17]. Leggatt, H. (2010). Rebuild Brand Loyalty with Social Media. Biz Report.

[18]. Libai, B., Bolton, R., Bügel, M. S., De Ruyter, K., Götz, O., Risselada, H., \& Stephen, A. T. (2010). Customer-to-customer interactions: broadening the scope of word of mouth research. Journal of service research, 13(3), 267-282.

[19]. Marketing Science Institute (2016). p. 1 - Marketing Science Institute (2016). Research priorities 20162018. http://www.msi.org/uploads/articles/MSI_RP1618.pdf.

[20]. Miller, R., \& Lammas, N. (2010). Social media and its implications for viral marketing. Asia Pacific Public Relations Journal, 11(1), 1-9.

[21]. Muntinga, D. G., Moorman, M., \& Smit, E. G. (2011). Introducing COBRAs: Exploring motivations for brand-related social media use. International Journal of advertising, 30(1), 13-46.

[22]. Naylor, R. W., Lamberton, C. P., \& West, P. M. (2012). Beyond the "like" button: The impact of mere virtual presence on brand evaluations and purchase intentions 
n social media settings. Journal of Marketing, 76(6), 105-120.

[23]. Patterson, A. (2012). Social-networkers of the world, unite and take over: A meta-introspective perspective on the Facebook brand. Journal of Business Research, 65(4), 527-534.

[24]. Pentina, I., Gammoh, B. S., Zhang, L., \& Mallin, M. (2013). Drivers and outcomes of brand relationship quality in the context of online social networks. International Journal of Electronic Commerce, 17(3), 63-86.

[25]. Ross, C., Orr, E. S., Sisic, M., Arseneault, J. M., Simmering, M. G., \& Orr, R. R. (2009). Personality and motivations associated with Facebook use. Computers in human behavior, 25(2), 578-586.

[26]. Sands, S., Harper, E., \& Ferraro, C. (2011). Customerto-noncustomer interactions: Extending the 'social'dimension of the store environment. Journal of Retailing and Consumer Services, 18(5), 438-447.

[27]. Schouten, J. W. (1991). Selves in transition: Symbolic consumption in personal rites of passage and identity reconstruction. Journal of consumer research, 17(4), 412-425.

[28]. Shao, G. (2009). Understanding the appeal of user-generated media: a uses and gratification perspective. Internet research.

[29]. Social, W. A. (2020). Hootsuite.(2020). Digital 2020July Global Statshot report. https://wearesocial. com/blog/2020/07/more-than-half-of-the-people-onearth-now-use-social-media.

[30]. Sook Kwon, E., Kim, E., Sung, Y., \& Yun Yoo, C. (2014). Brand followers: Consumer motivation and attitude towards brand communications on Twitter. International Journal of Advertising, 33(4), 657-680.

[31]. Statista (2019). Number of Social Network Users in India from 2015 to 2018 with a forecast until 2023 (in millions).

https://www.statista.com/statistics/278407/number-

of-social-network-users-in-india/

[32]. Statista reports, Kantar IMRB ICUBE Report (2019). Digital and Social Media Landscape in India. https://sannams4.com/digital-and-social-medialandscape-in-india/

[33]. Statista (2020). Countries with the highest number of internet users as of December 2019. https://www.statista.com/statistics/262966/numberof-internet-users-in-selected-countries/

[34]. Statista (2020). Penetration of Leading Social Networks in India as of 3rd Quarter 2019 (in millions). https://www.statista.com/statistics/284436/indiasocial-network-penetration/ i [35]. Stokbur

ger-Sauer, N., Ratneshwar, S., \& Sen, S. (2012). Drivers of consumer-brand identification. International journal of research in marketing, 29(4), 406-418.

[36]. Van Doorn, J., Lemon, K. N., Mittal, V., Nass, S., Pick, D., Pirner, P., \& Verhoef, P. C. (2010). Customer engagement behavior: Theoretical foundations and research directions. Journal of service research, 13(3), 253-266. 